\title{
Applicability of Mixolab test with local wheat flours
}

\author{
DANiEl VÁzQUez ${ }^{\mathrm{a}^{*}}$ AND María C. Veira ${ }^{\mathrm{b}}$ \\ a Instituto Nacional de Investigación Agropecuaria (INIA), La Estanzuela, Ruta 50 km 11.500, Colonia, CP \\ 70000, Uruguay \\ b Molino Río Uruguay, General Aguilar 1215, Montevideo, Uruguay \\ ${ }^{*}$ Corresponding author \\ dvazquez@inia.org.uy \\ TEL: $+598-4574-8000$ \\ FAX: $+598-4574-8012$
}

Received: 20 May 2014; Published online: 18 April 2015

\begin{abstract}
Several types of equipment have been used to predict dough behaviour during breadmaking. The complexity of requirements means that no device is able to predict all the properties, and therefore, new tests are released continuously. The Chopin Mixolab mixes the dough at different temperatures, allowing the study of dough mixing properties, weakening, gelatinization, gel stability and retrogradation in one test. The objective of this work was to study the suitability of the Mixolab to predict rheological properties and breadmaking quality of local wheats. Flour was obtained from 29 wheat samples from different genotypes and environments. The correlation of results from traditional analyses (test weight, protein content, sedimentation volume, wet gluten, Falling Number, Alveograph and Farinograph) with Mixolab parameters was studied. The properties of two different bread types were compared with all these parameters. Stability and water absorption values from the Farinograph were highly correlated with the respective Mixolab parameters. It was concluded that wheat samples could be sorted by mixing properties in similar order independently of which method was used. Beyond that, gluten strength estimators obtained from these three rheological methods and the sedimentation volume test were highly correlated. Whilst the correlation of Mixolab parameters with pan loaf volume was not as high as traditional ones, Mixolab developing time, stability and C5 were the best correlated with the most important hearth bread characteristics. Studies performed by other researchers, using wheats from diverse origins, found different results. The need for empirical rheology evaluation with local wheat samples was proved.
\end{abstract}

Keywords: Mixolab; Rheolog; Wheat quality; Breadmaking 


\section{Nomenclature}

Mixolab variables:
C1: consistency at the maximum during dough development
C2: consistency at the minimum after protein denaturation
C3: consistency at the maximum during starch gelatinization
C4: consistency at the minimum after amylolytic activity
C5: $\quad$ consistency at the maximum after retrogradation
C3-C4: consistency drop from maximum due to gelatinization to minimum due to amylolytic activity
C5-C4: consistency increase from minimum due to amylolytic activity to maximum after retrogradation
$\alpha: \quad$ slope caused by protein weakening
$\beta$ : $\quad$ slope caused by pasting
$\gamma$ : $\quad$ slope caused by amylolytic degradation

\section{Introduction}

Wheat should possess good end-use quality in order to satisfy the needs of the market. The most important requirements for breadmaking quality are related to dough behaviour during the different stages of mechanical work and heat treatment of the breadmaking process. Dough response to these procedures should be determined in order to find the most suitable wheat.

Many devices have been proposed to predict wheat or flour behaviour during breadmaking (Carson, Edwards, Khan, Shewry, et al., 2009; Békés, 2012). Traditional instruments were developed to provide parameters with empirical relationships between their results and bread quality. They generate useful information, but the parameters obtained are not related with well defined physical properties (Rao, Mulvaney, \& Dexter, 2000). When fundamental dough rheological properties were studied, the results had limited applicability, and several aspects are not yet understood (Hadnadev, Hadnadev, Simurina, \& Filipcev, 2013; Stojceska \& Butler, 2012). In addition, the complexity of the requirements means that no single component explains most bread quality variability (Békés, 2012). While fundamental rheology needs more research, the wheat industry is seeking new devices to predict breadmaking properties in order to help to select the most suitable wheats.

Traditionally, the physical characteristics of South American wheat dough have been evaluated using the Alveograph and Farinograph. However, they are not always able to give all the necessary information on the physical char- acteristics of the dough (Vázquez, Watts, Lukow, Williams, \& Arntfield, 2005).

The Chopin Mixolab is a relatively new device designed to study several rheological characteristics of flour dough. In this instrument, $50 \mathrm{~g}$ of flour is mixed with water while torque is measured. Temperature is controlled during the whole process through an integrated water circuit controlled by specific computer software. Among its original aspects, is the possibility of studying mixing properties at different temperatures. During the mixing process, temperature can be varied, providing several characteristics of the dough. In a typical Mixolab analysis, initial mixing properties are measured at $30^{\circ} \mathrm{C}$. Then, the dough is heated up to $90^{\circ} \mathrm{C}$, which allows the study of the weakening of protein structure as the temperature goes from 30 to $60^{\circ} \mathrm{C}$ and starch gelatinization while the temperature is between 60 and $90^{\circ} \mathrm{C}$. The temperature is held for a few minutes in order to determine the stability of the starch gel that is formed. After this, the dough is cooled down, allowing retrogradation analysis. During the first years after its release, Mixolab reproducibility was verified in an international collaborative study and standards were released (Dubat, 2010). It allowed different kinds of studies, like the characterization of bread doughs enriched with fibre (Rosell, Santos, \& Collar, 2010), the modelling of dough mixing (Ohm, Simsek, \& Mergoum, 2012), and the determination of the effect of hydrocolloids on thermo-mechanical properties of dough (Rosell, Collar, \& Haros, 2007). It proved to be useful for studying protein aggregation and starch structural changes during 
dough mixing and heating (Rosell, AltamiranoFortoul, Don, \& Dubat, 2013) and appropriate to screen genotypes for dough strength (Koksel, Kahraman, Sanal, Ozay, \& Dubat, 2009). However, most authors suggest that further work is required in order to confirm its suitability.

Mixolab is an empirical device. Empirical rheological devices are often only valid within a very limited range of flours and conditions (Dobraszczyk \& Roberts, 1994). Therefore, their suitability should be evaluated for each use and each kind of samples.

The objective of this present research was to evaluate the suitability of the Mixolab to predict rheological properties and breadmaking quality of local wheats.

\section{Materials and Methods}

A total of 29 samples were obtained by cultivating 10 Uruguayan genotypes in 3 environments. The genotypes were nine varieties (INIA Carpintero, INIA Chimango, INIA Don Alberto, INIA Madrugador, INIA Mirlo, INIA Tijereta, Génesis 2346, Génesis 2354 and Génesis 2359) and one experimental line (LE 2360), all of them from the INIA wheat breeding program. All of them were hard red wheats, representing the quality variability of the wheats planted in the region. In order to get representative variability of the crop environments, they were grown in two Uruguayan locations in the core wheat growing region: Dolores (two years: 2008 and 2009) and Rodó (only during 2008). While 2009 was a rainy year, mostly during grain swelling, 2008 was dry, especially in Rodó. This was reflected in protein content (10.2\% in 2009 and $14.1 \%$ in 2008 ) and test weight $(75.0 \mathrm{~kg} / \mathrm{hL}$ in Rodó in 2008 , $76.2 \mathrm{~kg} / \mathrm{hL}$ in Dolores in 2008 and $78.1 \mathrm{~kg} / \mathrm{hL}$ in Dolores in 2009) of the harvested samples.

American Association of Cereal Chemists International methods (AACC, 2000) were used to determine test weight (AACC Approved Method 55-10) and grain protein content (AACC Approved Method 46-12). Refined flour was obtained using Bühler Mill MLU 202 (AACC Approved Method 26-21A; AACC (2000)). Sedimentation volume was measured according to Peña, Amaya, Rajaram, and Mujeebkazi (1990), using $1 \mathrm{~g}$ of sample and including sodium dodecyl sulphate (SDS) in the solvent. Two traditional rheological tests were performed: Alveograph (AACC Approved Method 54-30; AACC (2000)) and Farinograph (AACC Approved Method 5421; AACC (2000)). In order to fully characterize the sample set, wet gluten (AACC Approved Method 38-12; AACC (2000)) and Falling Number (AACC Approved Method 56-81B; AACC (2000)) were determined. All tests were performed in duplicate.

Two different breadmaking tests were performed. The traditional pan loaf bread test was done according to the AACC 10-10B, and volume was determined. A hearth loaf test, designed to evaluate flours to be used for French-type Uruguayan bread, was also performed (Paulley, Vazquez, Lysenko, \& Preston, 2004). Besides volume, form ratio (maximum height/maximum width) and a subjective crumb score were determined. All baking tests were repeated, with duplicates performed on different days.

Mixolab (Perten Instruments, Sweden) tests were done according to the maker's specifications, standardized at AACCI 54-60.01. Thirteen parameters were determined (Figure 1 ). Water absorption (WA) was defined as the percentage of water required to obtain the first peak (C1) of $1.1 \mathrm{Nm}(+/-0.05 \mathrm{Nm})$. Developing time was defined as the time in minutes that it took to reach C1. Stability (ST) was considered as the time in minutes when the consistency was above the first peak maximum minus $11 \%$. Consistency was measured in Newton meters $(\mathrm{Nm})$ at five different times: $\mathrm{C} 1$ was the maximum during dough development, C2 was the minimum after protein denaturation, C3 was the maximum during starch gelatinization, C4 was the minimum after amylolytic activity and C5 was the maximum after retrogradation. Two secondary parameters were calculated: the differences between C3-C4 and $\mathrm{C} 5-\mathrm{C} 4$. The slope was determined at three points: $\alpha$ was the one caused by protein weakening, $\beta$ was the one caused by pasting and $\gamma$ was the one caused by amylolytic degradation.

Single correlation coefficients were calculated using the CORR procedure of the SAS package (SAS, Version 8.0, 1999, Statistical Analysis Institute Cary, NC, USA). 


\section{Results and Discussion}

\subsection{Samples set characterization}

The samples were selected in order to have variability in genetics (10 genotypes) and environments (two locations, two growing seasons). The characterization of the sample set is presented in Table 1. As expected, wide variability was observed in all parameters. Extreme values of test weight and protein content could be explained mostly by environmental effects (Vázquez et al., 2012). Contrasting environmental effects using different genotypes also generated wide ranges in dough physical properties like Alveograph W (180-462j/10000), Alveograph P/L (0.4-3.1) and Farinograph stability (7.5-79.0). This variation was representative of the observations with local wheats (Castro et al., 2014), making this set suitable to evaluate applicability of new methodology, like the Mixolab, with local wheats.

\subsection{Correlations with traditional variables}

The correlation between traditional and Mixolab variables was analyzed (Table 2). Although test weight was correlated with several Mixolab variables, since most of them were also correlated with grain protein but with the opposite sign, it was presumed that the correlations between test weight and Mixolab variables were due to the known negative correlation between grain protein content and test weight (Vázquez et al., 2012).

The highest correlation coefficient of Falling Number was with C3-C4. This is a parameter related with gelatinization and amylolytic activity. These two properties are both known to be related with Falling Number test (MacArthur, Dappolonia, \& Banasik, 1981).

Several Mixolab variables were correlated with grain protein, being $\mathrm{C} 1$ the one with highest correlation coefficient. This made sense, since it can be presumed that the first peak was caused by the gluten network formation (Bloksma, 1990). Correlations with wet gluten were lower than with protein content, with the only exception being water absorption.

As expected, equivalent parameters of Farino- graph and Mixolab were highly correlated. The maximum correlation coefficient observed $(\mathrm{r}=$ $0.93, \mathrm{P}<0.001)$ was the one that compared the stability of both devices. Working with a very different set of samples, Rosell et al. (2010) also observed significant correlation between these parameters, although with a lower coefficient $(0.77, \mathrm{P}<0.05)$. Similarly, several Mixograph parameters were reported to be significantly correlated $(\mathrm{r}=0.39-0.93, \mathrm{P}<0.001)$ with Mixolab stability (Caffe-Treml, Glover, Krishnan, \& Hareland, 2010). The correlation coefficient for water absorption in our work was also highly significant and higher than in these previous studies. These results suggested that wheat samples could be sorted by mixing properties in similar order independently of which method is used.

Three Mixolab variables (developing time, stability and C1) were significantly correlated with Farinograph stability. The same parameters were the only correlated with Alveograph W and sedimentation volume. Farinograph stability, Alveograph $\mathrm{W}$ and sedimentation volume are three parameters used to predict dough strength (Vázquez et al., 2012). These results demonstrated that Mixolab data were equivalent to the traditional methods to predict dough strength. Hadnadev et al. (2013) found that three flour samples could be sorted by dough strength in the same order using Alveograph, Farinograph or Mixolab parameters. In our work, a high correlation was observed between traditional and Mixolab strength estimators using a more complex set of samples. Therefore, it was concluded that these devices could be used independently to select wheats by strength.

No other Alveograph variable had a significant correlation with any Mixolab one.

\subsection{Correlations with traditional variables}

Since the devices produce no fundamental rheological parameters, their relevance is defined by their suitability to predict breadmaking quality. Therefore, although it is very important to study the relationship with traditional parameters, it is even more important to evaluate the correlations of the Mixolab variables with breadmaking 
Table 1: Mean, minimum, maximum and standard deviation of quality parameters

\begin{tabular}{|c|c|c|c|c|}
\hline Parameter & Mean & Minimum & Maximum & $\begin{array}{l}\text { Standard } \\
\text { deviation }\end{array}$ \\
\hline Test weight $(\mathrm{kg} / \mathrm{hL})$ & 76.5 & 68.8 & 81.5 & 3.7 \\
\hline Falling number (sec) & 393 & 158 & 583 & 113 \\
\hline Sedimentation volume $(\mathrm{mL} / \mathrm{g})$ & 16.5 & 10.5 & 22.5 & 3.9 \\
\hline Grain protein (\%, dry basis) & 12.7 & 9.9 & 15.6 & 2.0 \\
\hline Wet gluten (\%), as is basis & 32.1 & 18.9 & 45.9 & 7.5 \\
\hline \multicolumn{5}{|l|}{ Alveograph parameters } \\
\hline $\mathrm{W}(\mathrm{J} / 10000)$ & 293 & 180 & 462 & 77.9 \\
\hline $\mathrm{P}(\mathrm{mm})$ & 84 & 53 & 147 & 19.3 \\
\hline $\mathrm{L}(\mathrm{mm})$ & 94 & 47 & 146 & 28.3 \\
\hline $\mathrm{P} / \mathrm{L}$ & 1.0 & 0.4 & 3.1 & 0.58 \\
\hline \multicolumn{5}{|l|}{ Farinograph parameters } \\
\hline Stability (min) & 32.2 & 7.5 & 79.0 & 18.0 \\
\hline Absorption (\%) & 56.1 & 48.5 & 63.7 & 3.6 \\
\hline \multicolumn{5}{|l|}{ Mixolab parameters } \\
\hline Water absorption (\%) & 57.9 & 52.5 & 66.5 & 3.2 \\
\hline Development time (min) & 13.1 & 4.2 & 28.2 & 7.0 \\
\hline Stability (min) & 25.3 & 3.1 & 62.9 & 17.2 \\
\hline $\mathrm{C} 1(\mathrm{Nm})$ & 1.11 & 1.03 & 1.29 & 0.05 \\
\hline $\mathrm{C} 2(\mathrm{Nm})$ & 0.41 & 0.27 & 0.51 & 0.06 \\
\hline $\mathrm{C} 3(\mathrm{Nm})$ & 1.87 & -2.05 & 2.44 & 0.81 \\
\hline $\mathrm{C} 4(\mathrm{Nm})$ & 1.66 & -2.20 & 2.25 & 0.85 \\
\hline C5 (Nm) & 3.08 & 1.09 & 3.80 & 0.66 \\
\hline $\mathrm{C} 3-\mathrm{C} 4(\mathrm{Nm})$ & 0.21 & -0.11 & 0.88 & 0.22 \\
\hline $\mathrm{C} 5-\mathrm{C} 4(\mathrm{Nm})$ & 1.38 & 0.00 & 5.55 & 1.03 \\
\hline$\alpha$ & -0.04 & -0.13 & 0.03 & 0.04 \\
\hline$\beta$ & 0.51 & 0.01 & 0.84 & 0.24 \\
\hline$\gamma$ & -0.03 & -0.09 & 0.02 & 0.03 \\
\hline
\end{tabular}

Mixolab parameters: C1-C5: consistency at dough development, after protein reduction, at starch gelatinization, after amylolytic activity and at retrogradation, respectively; C3-C4 and C4-C5: differences between maximum and minimum; $\alpha$ : protein weakening slope; $\beta$ : pasting slope; $\gamma$ : amylolytic degradation speed 
Mixolab test with local wheat $\mid 83$

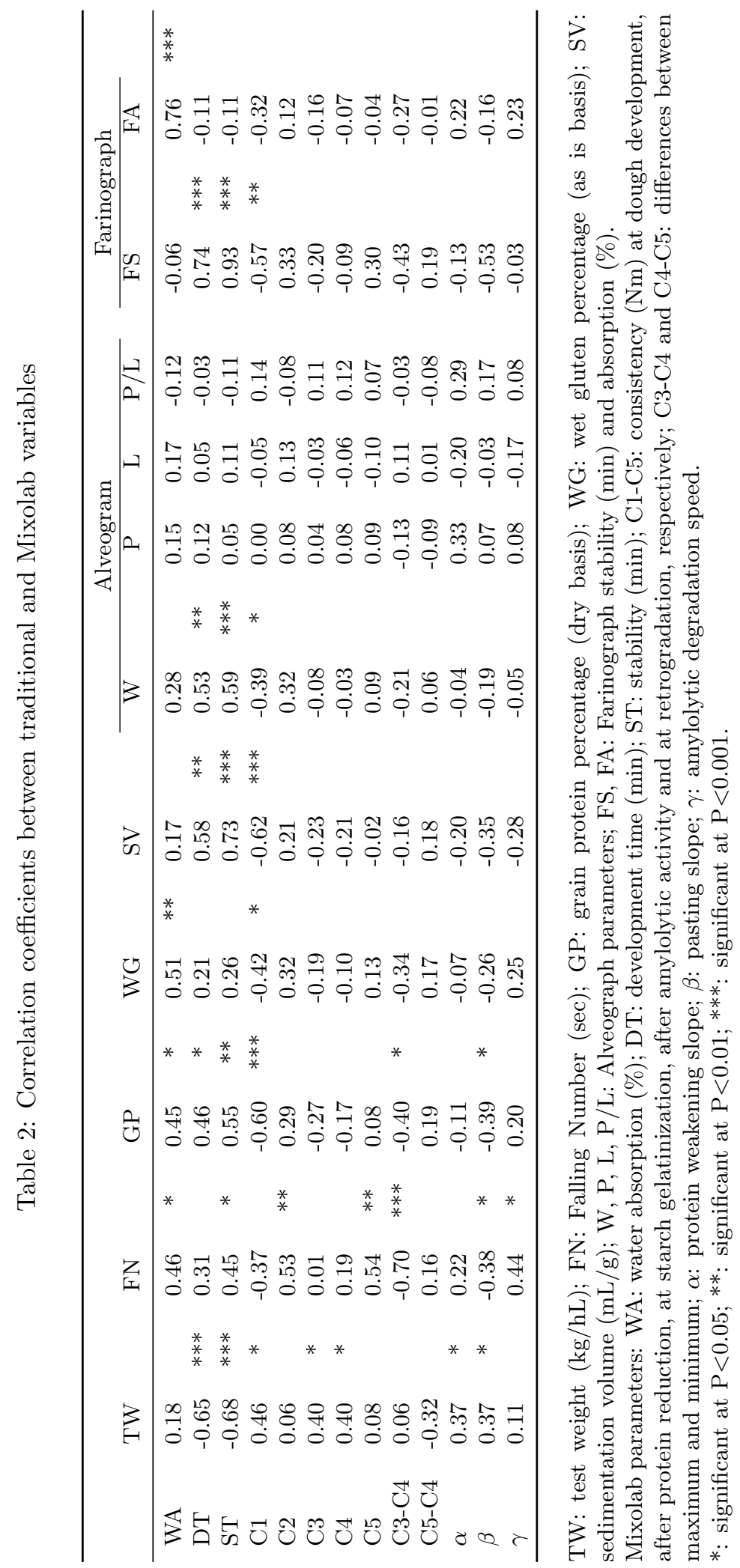

IJFS | April 2015 | Volume 4 | pages 78-87 
84 | Vázquez and Veira

Table 3: Correlation coefficients between breadmaking variables and quality predictors

\begin{tabular}{|c|c|c|c|c|c|c|c|c|}
\hline \multirow[b]{2}{*}{ Parameter } & \multirow{2}{*}{\multicolumn{2}{|c|}{$\begin{array}{c}\text { Pan loaf } \\
\text { volume }(\mathrm{mL})\end{array}$}} & \multicolumn{6}{|c|}{ Hearth bread } \\
\hline & & & Volun & $(\mathrm{mL})$ & Form & ratio & Crumb & openess \\
\hline Falling number (seg) & 0.00 & & -0.15 & & 0.14 & & -0.37 & $*$ \\
\hline Sedimentation volume $(\mathrm{mL} / \mathrm{g})$ & 0.52 & $* *$ & 0.62 & $* * *$ & 0.34 & & 0.33 & \\
\hline Grain protein (\%, dry basis) & 0.50 & $* *$ & 0.34 & & 0.11 & & 0.19 & \\
\hline Wet gluten $(\%)$, as is basis & 0.51 & $* *$ & 0.11 & & -0.06 & & -0.02 & \\
\hline \multicolumn{9}{|l|}{ Alveograph parameters } \\
\hline $\mathrm{W}(\mathrm{J} / 10000)$ & 0.52 & $* *$ & 0.39 & $*$ & 0.30 & & 0.09 & \\
\hline $\mathrm{P}(\mathrm{mm})$ & -0.17 & & -0.17 & & 0.07 & & -0.30 & \\
\hline $\mathrm{L}(\mathrm{mm})$ & 0.63 & $* * *$ & 0.39 & $*$ & 0.04 & & 0.30 & \\
\hline $\mathrm{P} / \mathrm{L}$ & -0.45 & & -0.27 & & -0.01 & & -0.25 & \\
\hline \multicolumn{9}{|l|}{ Farinograph parameters } \\
\hline Stability (min) & 0.16 & & 0.49 & $* *$ & 0.43 & $*$ & 0.25 & \\
\hline Absorption (\%) & 0.29 & & -0.15 & & -0.21 & & -0.23 & \\
\hline \multicolumn{9}{|l|}{ Mixolab parameters } \\
\hline Water absorption (\%) & 0.11 & & -0.03 & & -0.20 & & -0.05 & \\
\hline Development time (min) & 0.21 & & 0.39 & $*$ & 0.37 & & 0.15 & \\
\hline Stability (min) & 0.24 & & 0.37 & * & 0.37 & $*$ & 0.12 & \\
\hline $\mathrm{C} 1(\mathrm{Nm})$ & -0.19 & & -0.34 & & -0.20 & & -0.17 & \\
\hline $\mathrm{C} 2(\mathrm{Nm})$ & 0.15 & & -0.20 & & 0.22 & & -0.45 & $*$ \\
\hline C3 (Nm) & -0.15 & & -0.19 & & -0.09 & & -0.24 & \\
\hline $\mathrm{C} 4(\mathrm{Nm})$ & -0.17 & & -0.20 & & 0.01 & & -0.31 & \\
\hline C5 (Nm) & -0.07 & & -0.23 & & 0.39 & $*$ & -0.49 & $* *$ \\
\hline $\mathrm{C} 3-\mathrm{C} 4(\mathrm{Nm})$ & 0.05 & & 0.00 & & -0.39 & $*$ & 0.22 & \\
\hline $\mathrm{C} 5-\mathrm{C} 4(\mathrm{Nm})$ & 0.01 & & 0.08 & & 0.22 & & 0.04 & \\
\hline$\alpha$ & -0.31 & & -0.31 & & -0.19 & & -0.31 & \\
\hline$\beta$ & -0.10 & & -0.20 & & -0.15 & & -0.03 & \\
\hline$\gamma$ & -0.09 & & -0.31 & & 0.10 & & -0.31 & \\
\hline
\end{tabular}

Mixolab parameters: C1-C5: consistency at dough development, after protein reduction, at starch gelatinization, after amylolytic activity and at retrogradation, respectively; C3-C4 and C4-C5: differences between maximum and minimum; $\alpha$ : protein weakening slope; $\beta$ : pasting slope; $\gamma$ : amylolytic degradation speed.

*: significant at $\mathrm{P}<0.05$; **: significant at $\mathrm{P}<0.01$; ***: significant at $\mathrm{P}<0.001$. 
characteristics. Two different bread tests were used for the evaluation (Table 3). One was a pan bread test, similar to the one made in industrial bakeries, while the other one was a hearth type, representative of that produced by small bakeries. Requirements vary among different types of bread (Sliwinski, Kolster, \& van Vliet, 2004; Vázquez et al., 2005).

The highest correlation coefficient with pan loaf volume was observed with Alveograph L or "extensibility". The importance of extensibility was previously reported with South American wheats (Vázquez \& Watts, 2004) and also with an independent set of samples (Caffe-Treml et al., 2011). No Mixolab parameter had significant correlation with pan loaf volume. However, Ohm et al. (2012) working with 30 American hard red spring wheat samples (five genotypes in six locations) found a positive and significant correlation between AACCI 10-10B pan loaf volume and several Mixolab parameters, including water absorption, developing time, stability and C2. Using 16 Turkish wheats, Koksel et al. (2009) found the only Mixolab parameters that correlated with pan bread volume, obtained with a modified procedure, were C3, C4, C5 and $\alpha$ ( $\mathrm{r}=-0.514$ - $0.614, \mathrm{P}<0.01)$. With flours obtained from 18 wheat genotypes grown in 20 environments, Caffe-Treml et al. (2010) observed a correlation between pan loaf volume obtained with an AACC 10-09.01 method and several Mixolab parameters. The best correlations they observed were for water absorption $(\mathrm{r}=0.44, \mathrm{P}<0.001)$ when they correlated individual samples $(n=360)$ and for stability $(\mathrm{r}=0.70, \mathrm{P}<0.001)$ when they correlated means of genotypes $(n=18)$. Lack of consistency among different results could be explained by the small number of samples used; more likely, it could be explained by the different characteristics of the wheats under study. These differences were also observed in research involving other rheological properties (Caffe-Treml et al., 2011). Therefore, in order to establish the suitability of a new method, it is essential to evaluate it with a set of samples representative of the population that will use it. In particular, Latin American wheats have a very wide variety of quality characteristics (Vázquez et al., 2012).

Sedimentation volume was the parameter most closely correlated with hearth bread volume.
This means that hearth bread had different requirements than pan bread, which has been proposed previously (Carson et al., 2009). Pan bread has the walls of the baking tin to help to support the structure. Therefore, hearth bread strength requirements are higher in order to help it retain its shape during the baking process (Sliwinski et al., 2004). This theory is supported not only by the high correlation between the hearth bread volume with sedimentation volume, but also the significant correlation with Farinograph stability, Alveograph W (also called "baking strength"), and two Mixolab strength estimators: developing time and stability.

For hearth bread, form is as important as volume and form ratio, defined as maximum height/ maximum width of the loaf, is an important predictor of quality (Faergestad, Molteberg, \& Magnus, 2000). Both Farinograph and Mixolab stabilities were significantly correlated with form ratio. Not only was strength related to hearth loaf form, gelatinization seemed to play a key role too, since C5 was significantly correlated with form ratio.

Crumb openness is another relevant characteristic of French-type bread. It can be evaluated with subjective scores (Faergestad et al., 2000). None of the traditional parameters studied had as good correlation as C5, which was explained by the influence of starch properties on crumb characteristics. In summary, while Mixolab parameters were not as correlated as traditional ones with pan bread volume, Mixolab developing time, stability and C5 were the best correlated with the three characteristics of hearth bread.

\section{Conclusions}

This study confirmed Mixolab suitability to evaluate wheat dough strength of Uruguayan wheats. Correlation coefficients indicated that its parameters were at least as good as the traditional ones. It was concluded that it could be useful for both screening in breeding trials and evaluation of wheat cargos.

Even though it proved to be good for strength, correlation of loaf volume with Mixolab parameters was not as good as with the Alveograph ones. Neither of the Mixolab parameters used 
in this study was intended to estimate extensibility, which is a very important requirement for good bread volume. However, the Mixolab generates a great volume of information, and other parameters could be generated. If it is desired to estimate extensibility, the suitability of other parameters obtained from this device should be evaluated. It did prove to be useful, and even better than traditional devices, in the prediction of the other bread characteristics. This seemed to be due to the unique characteristics of the new device to change temperatures during the analysis. Therefore, it is concluded that the information it generates complements that obtained from traditional equipment.

Several of the results from this work were comparable with others performed with different set of samples but a number of differences were observed (Caffe-Treml et al., 2010; Koksel et al., 2009; Ohm et al., 2012), confirming that the evaluation of empirical rheology should be performed with samples obtained from the population that will be tested. These trends should be confirmed with larger populations.

\section{Acknowledgements}

This work was realized and supported by INIA (National Institute of Agriculture Research, Uruguay) and Molino Río Uruguay S.A. (Montevideo, Uruguay). Preliminary results were presented at the II Latin American Cereal Conference ICC, at Santiago, Chile, 2011.

\section{References}

AACC. (2000). American association of cereal chemists. Approved Methods of the AACC. 10th Ed. Methods 10-10B, 26-21A, 38-12, 46-12, 54-21, 54-30, 55-10 and 56-81B, St. Paul: The Association.

Békés, F. (2012). New aspects in quality related wheat research: ii. new methodologies for better quality wheat. Cereal Research Communications, 40(3), 307-333. doi:10 . 1556/CRC.2012.0003

Bloksma, A. H. (1990). Rheology of the breadmaking process. Cereal Foods World, $35(2), 228-236$.
Caffe-Treml, M., Glover, K. D., Krishnan, P. G., \& Hareland, G. A. (2010). Variability and relationships among mixolab, mixograph, and baking parameters based on multienvironment spring wheat trials. Cereal Chemistry, 87(6), 574-580. doi:10.1094/ CCHEM-04-10-0068

Caffe-Treml, M., Glover, K. D., Krishnan, P. G., Hareland, G. A., Bondalapati, K. D., \& Stein, J. (2011). Effect of wheat genotype and environment on relationships between dough extensibility and breadmaking quality. Cereal Chemistry, 88(2), 201208. doi:10.1094/CCHEM-08-10-0111

Carson, G. R., Edwards, N. M., Khan, K., Shewry, P. R., et al. (2009). Criteria of wheat and flour quality. Wheat: chemistry and technology, (Ed. 4), 97-118.

Castro, M., Loza, W., Castro, B., Cardozo, V., Pereyra, S., Germán, S., ... Olivieri, V. (2014). Resultados experimentales de la Evaluación Nacional de cultivares de trigo, cebada, colza, triticale y trigo doble propósito de los últimos tres años. Período 2011-2012-2013. Resultados experimentales N.14. Convenio INASE-INIA. Retrieved from www.inia.org.uy/convenio inase_inia / Evaluacion_CI / Ano2013 / JornadaInvierno2014.pdf

Dobraszczyk, B. \& Roberts, C. (1994). Strain hardening and dough gas cell-wall failure in biaxial extension. Journal of Cereal Science, 20(3), 265-274. doi:10 . $1006 /$ jcrs . 1994.1066

Dubat, A. (2010). A new AACC international approved method to measure rheological properties of a dough sample. Cereal Foods World (CFW), 55(3), 150-153. doi:10 . 1094/CFW-55-3-0150

Faergestad, E. M., Molteberg, E. L., \& Magnus, E. (2000). Interrelationships of protein composition, protein level, baking process and the characteristics of hearth bread and pan bread. Journal of Cereal Science, 31(3), 309-320. doi:10.1006/jcrs.1999.0304

Hadnadev, M., Hadnadev, T. D., Simurina, O., \& Filipcev, B. (2013). Empirical and fundamental rheological properties of wheat flour dough as affected by different climatic con- 
Mixolab test with local wheat $\mid 87$

ditions. Journal of Agricultural Science and Technology, 15 (S), 1381-1391.

Koksel, H., Kahraman, K., Sanal, T., Ozay, D. S., \& Dubat, A. (2009). Potential utilization of mixolab for quality evaluation of bread wheat genotypes. Cereal Chemistry, 86(5), 522-526. doi:10.1094/CCHEM-86-5-0522

MacArthur, L. A., Dappolonia, B. L., \& Banasik, O. J. (1981). The falling number test - what is it and how does it work. North Dakota Farm Research, 38(5), 15-22.

Ohm, J.-B., Simsek, S., \& Mergoum, M. (2012). Modeling of dough mixing profile under thermal and nonthermal constraint for evaluation of breadmaking quality of hard spring wheat flour. Cereal Chemistry, 89(2), 135-141. doi:10.1094/CCHEM-0711-0095

Paulley, G., Vazquez, D., Lysenko, E., \& Preston, K. R. (2004). Development of a laboratory baking test for uruguayan french style hearth bread using canadian wheat flour. Canadian Journal of Plant Science, 84 (4), 949-954.

Peña, R. J., Amaya, A., Rajaram, S., \& Mujeebkazi, A. (1990). Variation in quality characteristics associated with some spring 1b/1r translocation wheats. Journal of $\mathrm{Ce}$ real Science, 12(2), 105-112.

Rao, V. K., Mulvaney, S. J., \& Dexter, J. E. (2000). Rheological characterisation of long- and short-mixing flours based on stress-relaxation. Journal of Cereal Science, 31(2), 159-171. doi:10.1006/jcrs . 1999.0295

Rosell, C. M., Altamirano-Fortoul, R., Don, C., \& Dubat, A. (2013). Thermomechanically induced protein aggregation and starch structural changes in wheat flour dough. Cereal Chemistry, 90(2), 89-100. doi:10 . 1094/CCHEM-05-12-0056-R

Rosell, C. M., Collar, C., \& Haros, M. (2007). Assessment of hydrocolloid effects on the thermo-mechanical properties of wheat using the mixolab. Food Hydrocolloids, 21(3), 452-462. doi:10.1016/j. foodhyd.2006.05. 004

Rosell, C. M., Santos, E., \& Collar, C. (2010). Physical characterization of fiber-enriched bread doughs by dual mixing and temper- ature constraint using the mixolab(a (r)). European Food Research and Technology, 231(4), 535-544. doi:10.1007/s00217-0101310-y

Sliwinski, E. L., Kolster, P., \& van Vliet, T. (2004). On the relationship between large-deformation properties of wheat flour dough and baking quality. Journal of Cereal Science, 39(2), 231-245. doi:10.1016/ j.jcs.2003.10.005

Stojceska, V. \& Butler, F. (2012). Investigation of reported correlation coefficients between rheological properties of the wheat bread doughs and baking performance of the corresponding wheat flours. Trends In Food Science \& Technology, 24(1), 13-18. doi:10. 1016/j.tifs.2011.09.005

Vázquez, D. \& Watts, B. (2004). The gluten proteins. In D. L. et al. (Ed.), (Chap. Gluten extensibility: a key factor in Uruguayan wheat quality, pp. 279-284). Cambridge: The Royal Society of Chemists. doi:10 . 1039/9781847552099

Vázquez, D., Watts, B., Lukow, O., Williams, P., \& Arntfield, S. (2005, September). Dough extensional properties and the quality of hearth and pan breads. Paper presented at the American Association of Cereal Chemists International Annual Meeting, Orlando, Florida.

Vázquez, D., Berger, A. G., Cuniberti, M., Bainotti, C., de Miranda, M. Z., Scheeren, P. L., ... Peña, R. J. (2012). Influence of cultivar and environment on quality of latin american wheats. Journal of Cereal Science, 56(2), 196-203. doi:10.1016/j.jcs. 2012.03 .004 